
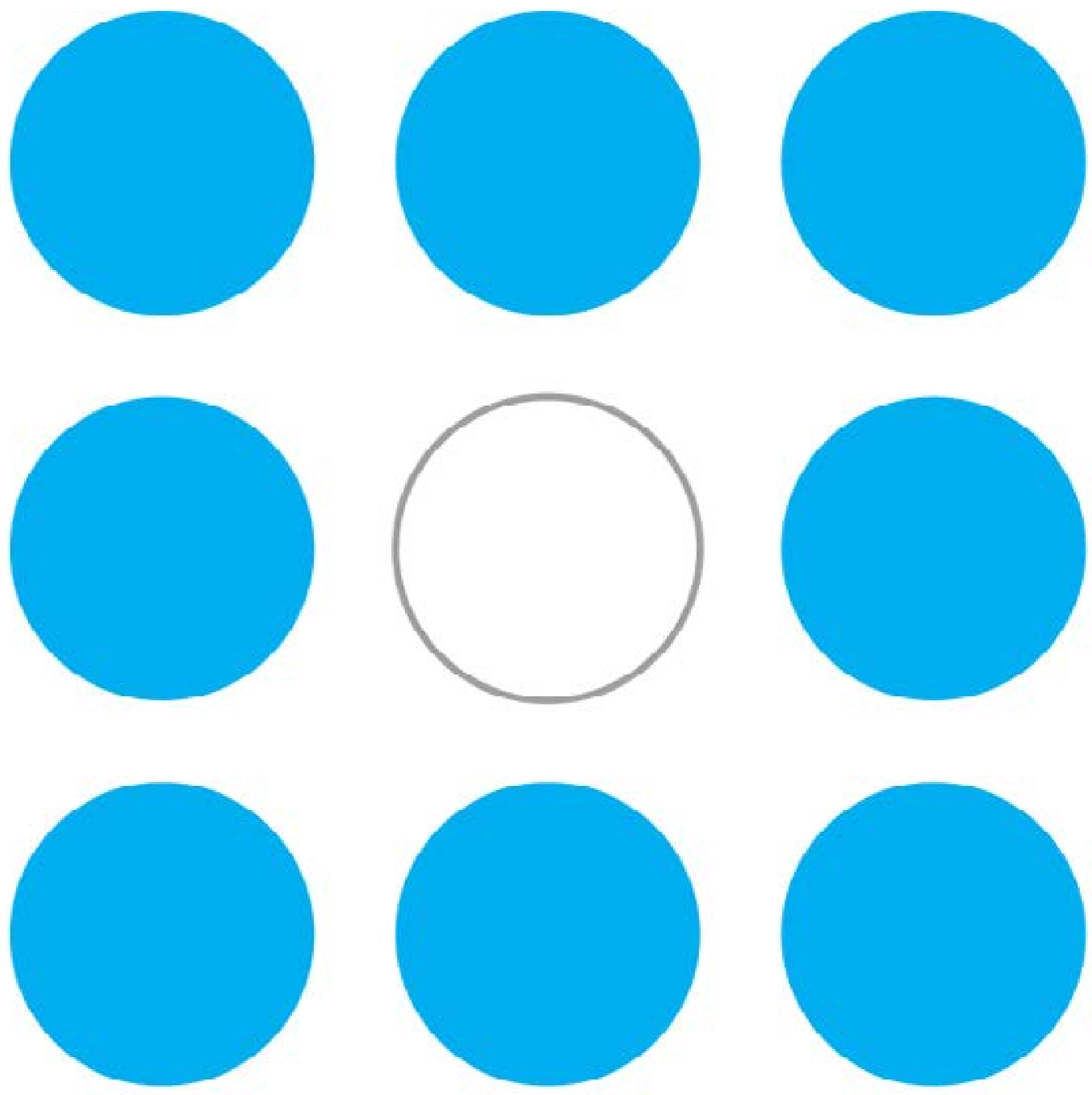

Núvol | Nube | Cloud 

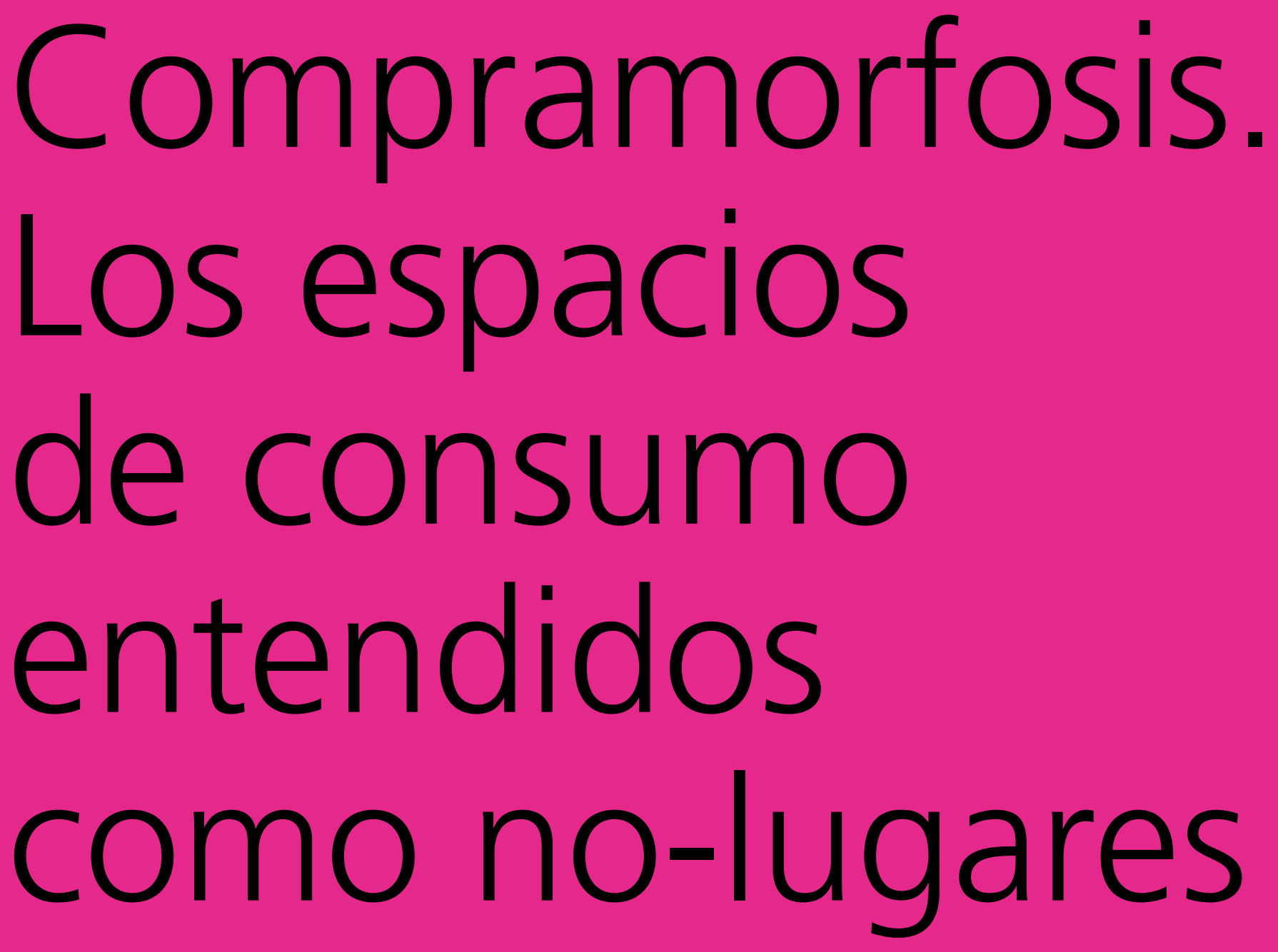

Jorge Becerril 


\section{Compramorfosis. Los espacios de consumo entendidos como no-lugares}

Buying-Morphosis. Consuming spaces understood as non-places

Jorge Becerril $^{1}$ 
COMPRAMORFOSIS. LOS ESPACIOS DE CONSMO

ENTENDIDOS COMO NO-LUGARES

\title{
Resumen
}

Este trabajo aborda la relación entre el concepto de sobremodernidad, planteado por el antropólogo francés Marc Augé, y los espacios de consumo contemporáneos, tomando en cuenta sus implicaciones con el usuario y la realidad aparente. Es un análisis de algunos de los aspectos conceptuales de la sobremodernidad y su aplicación en diversos espacios de consumo, basado en tres distinciones; Multiplicidad y particularización; el consumo emocional y el concepto abierto-cerrado. Este análisis nos permite determinar cómo en la actualidad existe una resignificación del espacio de consumo contemporáneo para ser considerado como un no-lugar.

Palabras clave | espacio de consumo; sobremodernidad; hiperrealidad; no-lugares.

\begin{abstract}
This work deals with the relationship between the concept of over-modernity, raised by the French anthropologist Marc Augé, and the contemporary consumption spaces, taking into account their implications with the user and the apparent reality. It is an analysis of some conceptual aspects of the over-modernity and its application in various consumption spaces, based in three differences: Multiplicity and particularization; the emotional consumption and the open-closed concept. This analysis allows us to determine that nowadays there is a new meaning of the contemporary consumption space to be considered as a non-place.
\end{abstract}

Keywords | Consumption space; over-modernity; hyperreality; non-places. 
COMPRAMORFOSIS. LOS ESPACIOS DE CONSMO

ENTENDIDOS COMO NO-LUGARES

"El espacio es lo que hace que todo no esté en el mismo lugar" Baudrillard Jean

En la contemporaneidad ${ }^{2}$ el espacio social ha adoptado nuevos y diferentes matices, los cuales están en constante cambio y evolución, esto hace que la configuración de las relaciones entre los objetos que instrumentan estos espacios y los individuos - y en consecuencia de los propios individuos entre sí- sufran mutaciones vertiginosas para encontrar un lugar en la realidad histórica del mundo.

"La modernidad... se acaba cuando — debido a múltiples razones- deja de ser posible hablar de la historia como de algo unitario" (Vattimo, 1990, 74-75). Nuestra historia se acelera, la información se multiplica y los espacios se enriquecen; desde cualquier punto podemos enterarnos de sucesos alrededor del planeta. Asimismo, el individuo es parte de una historia particularizada, no unitaria, que reivindica identidades, las espectaculariza, las arraiga en espacios desmaterializados ${ }^{3}$ y las confronta en una "aldea global" generales a este momento podríamos llamarlo el tiempo de la sobremodernidad.

La transición de lo moderno a lo sobremoderno, planteada por el antropólogo francés Marc Augé, no se da en una acepción del tiempo, sino en una concepción estilística de la realidad del espacio sobremoderno, "(...) es un signo no de un fin o de una difuminación, pero sí de una multiplicación y de una aceleración de los factores constitutivos de la modernidad" (Augé, 2009, 5), es un espacio ilimitado, multiforme e infinito, cual si fuera un mercado con exceso de información y posibilidades.

\footnotetext{
2 En el arte lo contemporáneo corresponde, según algunos autores, a las corrientes nacientes con el siglo XX, como el fauvismo, el dada, el surrealismo, etcétera; para fines de este trabajo entenderemos como contemporáneo a los acontecimientos que ocurren en la época actual, al presente inmediato y sus implicaciones espaciales.

3 La desmaterialización se maneja como una descomposición sobremoderna de la lectura de los signos, estos ya no se leen, en palabras de Paul Virilio, como figuras humanas o de animales, sino en imágenes rotas. Las imágenes rotas derivan en imágenes fractales, digitales y en la virtualización del espacio. 
En la sobremodernidad el exceso de información, de imágenes y de particularismos hace al individuo actor exclusivo de la historia, "la sobremodernidad convierte a lo antiguo (la historia) en un espectáculo específico, así como a todos los exotismos y particularismos locales" (Augé, 2008, 113).

Ahora bien, es importante señalar que la sobremodernidad actúa sobre una paradoja peculiar: por un lado, con este exceso de información, el mundo parece hacerse muy pequeño y trabajar sobre procesos globales de vinculación y comunicación a todo su largo y ancho, este se hace asequible para las individualidades, somos capaces de compartir imágenes, información y tecnologías con el resto de la humanidad. El mundo es nuestro punto de referencia, quien habita un espacio específico habita el mundo.

Sin embargo, y es aquí donde la paradoja toma relevancia, a la vez el mundo parece hacerse muy grande debido a la pluralidad cultural y las particularidades de toda índole: étnicas, sociales, religiosas, culturales, estéticas, sexuales, etcétera; estas se presentan en todo el mundo, a cada momento y con gran fuerza. Esta paradoja nos permite determinar que la concepción sobremoderna no se encuentra solo bajo el paradigma de la globalización, sino también a la luz de una explosión de particularidades.

La particularización parece una forma de reivindicar la identidad individual y local de cada caso, así pues, manifestaciones culturales como el "fervor guadalupano" en México, el "yanquismo" puro y arraigado en Estados Unidos, la "santería" brasileña o la nueva izquierda político-cultural en algunos países sudamericanos, refuerzan las identidades propias de una comunidad mientras dotan a los individuos de un sentimiento de extrañeza, incluso, en algunas ocasiones, de un sentimiento antagónico ante las diferentes expresiones culturales alrededor del mundo; así lo menciona Gianni Vattimo (1990) en el libro La sociedad transparente:

\section{(...) extrañamiento que es, además y al mismo tiempo, un liberarse por parte} de las diferencias, de los elementos locales, de todo lo que podríamos llamar, 
COMPRAMORFOSIS. LOS ESPACIOS DE CONSMO

ENTENDIDOS COMO NO-LUGARES

globalmente, el dialecto. En cuanto cae la idea de una racionalidad central de la historia, el mundo de la comunicación generalizada estalla en una multiplicidad de racionalidades "locales"(...) que toman la palabra, al no ser, por fin, silenciadas y reprimidas por la idea de que hay una sola forma verdadera de realizar la humanidad, en menoscabo de todas las peculiaridades, de todas las individualidades limitadas, efímeras y contingentes (84).

Es importante señalar que el paso de lo moderno a lo sobremoderno no implica una conquista conceptual o una negación ideológica de la modernidad.

La modernidad en términos de desencanto puede definirse por tres características:

la desaparición de los mitos de origen (...), la desaparición de todas las representaciones y creencias (...) del pasado y la aparición de mitos que no son más, esta vez, mitos del pasado, sino mitos del futuro(...) (Augé, 2009, 4).

Así, en este encanto por el futuro mítico, inició una escalada de pensamientos que establecen el espacio histórico de forma lineal y de concepción unitaria: conocimientos, expresiones y dialectos univaluados, de modo que en la sobremodernidad se "vive una situación explosiva, una pluralización que parece irrefrenable y que torna imposible concebir el mundo y la historia según puntos de vista unitarios" (Vattimo, 1990, 73).

Tomando en cuenta esta explosión de particularidades, la lógica del mercado de la información "reclama una continua dilatación de este mercado mismo, exigiendo, consiguientemente, que 'todo' se convierta, de alguna manera, en objeto de comunicación" (Vattimo, 1990, 79). Así, el espacio sobremoderno se concibe como un ducto de comunicación; en palabras de Michel de Certeau (2007) el espacio "(...) queda atrapado en la ambigüedad de una realización, transformado en un término pertinente de múltiples convenciones, planteado como el acto de un presente (o de un tiempo), y modificado por las transformaciones debidas a contigüidades sucesivas" (129). 
Todo espacio comunica, sin embargo, esta comunicación no se da en una relación de emisor-trasmisor corporalizados, ${ }^{5}$ como los esquemas comunicativos tradicionales lo plantean, sino en una relación simbólico-contractual que no permite centrar la importancia de la comunicación en los individuos o en el espacio, sino en lo simbólico.

Para que este proceso suceda las instrumentaciones simbólicas de los espacios deben establecer una relación individuo-símbolo-espacio que remplace la corporalización de los esquemas tradicionales. Las relaciones comunicativas de un espacio sobremoderno, como lo menciona Augé (2009), deben ser concebibles en lo simbólico-contractual y gestionables en el proceso comunicativo:

Las relaciones (...) deben ser, en un conjunto cultural dado, concebibles y gestionables. Concebibles ya que tienen cierta evidencia a los ojos de los que se reconocen en una misma colectividad: en este sentido son simbólicas (se dice por ejemplo que la bandera simboliza la patria, pero la simboliza sólo si un cierto número de individuos se reconocen en ella o a través de ella, si reconocen en ella el nexo que los une: ese nexo es lo que es simbólico) (2).

De este modo, diferentes conceptos como la deslocalización, ${ }^{6}$ la desterritorialización (véase Abbate \& Páez, 2007) y la desidentificación7 nos permiten entender mejor que "el espacio de la sobremodernidad está trabajado por una contradicción: tiene que ver con individuos (clientes, pasajeros, usuarios, oyentes) pero no están identificados, socializados, ni localizados (nombre, profesión, lugar de nacimiento, domicilio) más que a la entrada o a la salida" (Augé, 2008, 114).

\footnotetext{
5 Al hablar de corporalización en un proceso comunicativo evocamos los esquemas tradicionales de comunicación en donde la presencia física o material del emisor, el mensaje y el receptor eran necesarios para la comprensión y discusión del esquema.

6 Para Virilio el reino de la virtualidad informática conduce a una consecuencia esencial: la pérdida del sentido social del espacio como territorio físico y real. Por consiguiente, la desaparición del sentido del cuerpo propio, de los demás y del mundo; aparece la deslocalización; Virilio separa al "concepto" (espacio, arte, la lengua, etc.) de su localización de origen; no se le arraiga a un lugar en particular, funciona como un feedback, "existe como una emisión y recepción de una señal" (David \& Virilio, 2009, 2)

7 En los espacios de la sobremodernidad el individuo no testifica su identidad, sino que se despoja de ella para interactuar con el espacio, a este proceso se le denomina desidentificación. La sobremodernidad "nos muestra un mundo desasido de los parámetros de personalidad" (Vidal, 2007, 2).
} 
Podríamos decir que la sobremodernidad nos brinda espacios en donde una aparente identificación se da a través del particularismo simbólico. Este espacio se desmaterializa y se destemporaliza, el acto comunicativo y el espacio en sí desaparecen para lo global y se vislumbran solo en lo particular.

En concreto, el espacio de la sobremodernidad se entiende como una explosión de ausencias, es decir, la contemporaneidad está repleta y multiplicada por espacios simbólicos, espacios que sólo existen en la individualidad y que se ausentan en la colectividad; paradójicamente, sabemos que lo individualidad ausente testifica lo colectivo presente. Estas ausencias se revelan por medio de particularismos simbólicos, espacios efímeros y descorporalizados que adquieren materia simbólica, pues sólo en lo simbólico se permiten las relaciones. Esta ausencia permite adentrarnos en una segunda transición: la de los lugares a los no-lugares.

Los no-lugares: la soledad del símbolo, la no-identidad del individuo "Vivimos en un mundo que no hemos aprendido a mirar todavía" Marc Augé

Cuando la cultura muta los procesos de aprehensión y participación de la realidad deben adecuarse; aparecen nuevos y diversos espacios donde se desarrolla el entramado social que presupone las relaciones humanas. Como hemos analizado, la sobremodernidad es productora infinita de estos espacios, la evolución de los lugares a los no-lugares se experimenta a través de un vaciamiento de la individualidad donde sólo lo simbólico es testigo de lo que crea y alimenta al espacio. Para comprender mejor esta nueva conceptualización antropológica y su transición, primero se determinará qué es un "lugar".

\section{El lugar antropológico}

Según la antropóloga Mónica Lacarrieu (2013) “(...) el 'lugar' aparenta ser el resultado de un conjunto de elementos materiales y simbólicos sintetizados bajo el modelo aparentemente global" (15-16), es un "lugar" simbolizado, en lo colectivo, en el cual podemos ver, 
escuchar y oler, en cada uno de sus rincones, la identidad de quienes usan este espacio, las relaciones que los usuarios mantienen entre sí y la historia que éstos comparten. Es sencillo encontrar ejemplos de estos lugares en nuestra propia historia, pensemos en el pueblo de vacaciones familiares; la casa de los abuelos, sus calles, sus tradiciones, la ubicación de la plaza, los colores de la iglesia, la comida que se servía, la indumentaria de los pobladores, los saludos con el tendero o el mercado de los domingos; todo se relaciona entre sí y todo parece "hablar" sin compartir un mismo lenguaje. Es un lugar donde "(...) cada uno conoce su sitio y el de los otros, existe un conjunto de puntos de referencias espaciales, sociales e históricos" (Augé, 2009, 9).

Al mismo tiempo, es importante señalar que el lugar antropológico es partícipe directo en la construcción de la historia, la testifica, como lo menciona el sociólogo Pierre Bourdieu, se convierte en un campo social, "(...) como una esfera de la vida social que se ha ido autonomizando de manera gradual a través de la historia en torno a cierto tipo de relaciones, intereses y recursos propios (...)" (Guerra Manzo, 2010, 397). Quienes habitan el "lugar" se apropian del modelo simbólico que éste les ha heredado, es su responsabilidad preservarlo, y las interacciones sociales que en él se llevan a cabo contribuyen "a la conservación de su estructura o, en condiciones determinadas, a su transformación" (Bourdieu, 2002, 50-51).

Es así que, a pesar de las diferencias particulares que puedan existir entre las personas, la individualidad parece desaparecer o hacerse muy débil en el lugar antropológico, todo actúa simbólicamente para testificar el lugar, para defenderlo e inscribir en él la identidad, las relaciones sociales y la historia. Marc Augé (2008) describe el lugar antropológico como la unidad univalente de la realidad para los nativos del mismo:

\section{(...) el lugar lo ocupan los nativos que en él viven, trabajan, lo defienden, marcan} sus puntos fuertes, cuidan las fronteras pero señalan también la huella de las potencias infernales o celestes, la de los antepasados o de los espíritus que pueblan y animan la geografía íntima, como si no hubiera humanidad digna de ese nombre más que el lugar mismo del culto que se les consagra (49). 
Esta tarea incesante del usuario del lugar antropológico es lo que ha permitido hacer de nuestros "lugares" codificaciones simbólicas de relación; el hogar, la escuela y la oficina son ejemplos del lugar antropológico, "así al definir el lugar como un espacio en donde se puede leer la identidad, la relación y la historia, los no-lugares son espacios donde esta lectura no es posible" (10).

Sin embargo, debemos aclarar que esta transición no señala la muerte del "lugar antropológico", al contrario, podemos establecer que la correlación de ambos, en la realidad social, es lo que dota a las personas de identidad social e individualidad simbólica al mismo tiempo. "El lugar y el no lugar son más bien polaridades falsas: el primero no queda nunca completamente borrado y el segundo no se cumple nunca totalmente: son palimpsestos donde se reinscribe sin cesar el juego intrincado de la identidad y la relación" (84). Sólo a partir de este postulado podemos estudiar los "no-lugares" como complementarios al "lugar antropológico" y entender la existencia de la relación ambivalente del símbolo identitario ${ }^{8}$ con el símbolo individualizado. ${ }^{9}$ Así "como los lugares antropológicos crean lo social orgánico, los no lugares crean la contractualidad solitaria" (98).

\section{Los no-lugares}

Los no-lugares son espacios propios de la sobremodernidad, no existían en el pasado, son espacios de anonimato donde los individuos se instalan en un momento de espera y crean relaciones efímeras y fugaces con otros individuos en condiciones similares; relaciones furtivas de personas que nunca más se encontrarán ni volverán a verse.

Como lo hemos señalado, el espacio de la sobremodernidad es multiforme, así, los no-lugares en los que nos establecemos son cada vez más numerosos. Augé (2009) propone la

8 Entendido como todas las estructuras simbólicas que permiten arraigar el lugar antropológico a la realidad, reforzando la identidad social del espacio, estableciendo las relaciones y describiendo la historia del mismo.

9 El símbolo individualizado actúa en el espacio sobremoderno antagónicamente al símbolo identitario, premisa la individualización y las estructuras simbólicas particularizadas, no crea identidad, relaciones corporalizadas ni historia, sólo crea una individualidad simbólica. 
siguiente clasificación de estos espacios, relacionándolos con el simbolismo contractual de uso en que se inscriben.

- Los espacios de circulación: autopistas, áreas de servicio en las gasolineras, aeropuertos, vías aéreas, etcétera.

- Los espacios de consumo: súper e hipermercados, cadenas hoteleras, etcétera.

- Los espacios de comunicación: pantallas, cables, ondas con apariencia a veces inmateriales (10).

Los no-lugares "(...) tienen una existencia empírica y algunos geógrafos, demógrafos, urbanistas o arquitectos describen la extensión urbana actual como suscitando espacios que son verdaderos no-lugares" (11). La ruptura de los límites de la ciudad y el crecimiento desmedido del espacio nos incluyen en una nueva codificación de la utilización del mismo. Todo, a pesar de su extensión, parece unirse e incluirse en un solo entramado espacial.

Al analizar la clasificación y adaptarla a la realidad, podemos ver que estos no-lugares se relacionan y parecen imitarse entre sí: conduzco por la autopista mientras escucho las noticias en el radio, llego al supermercado y ocupo tiempo en elegir los productos que compraré, edecanes de diferentes productos me convencen de la compra; posteriormente, en la fila de la caja observo la pantalla que me habla de promociones; al pagar con mi tarjeta de crédito obtengo millas de viaje para el avión; finalmente, regreso de nuevo conduciendo por el camino. Este transcurso de tiempo que no se prolonga más de unas horas libera al individuo de las relaciones personales, se libera del peso del simbolismo identitario, sólo por unos momentos efímeros el individuo refuerza la "no-identidad".

Al conceptualizar la "no-identidad" la definimos como la condición que adquiere el individuo al utilizar un no-lugar, junto con los atributos particularizantes adoptados a la entrada de este. La "no-identidad" permite al individuo crear, a pesar del anonimato, relaciones contractuales, simbolizadas en imágenes virtualizadas y espectacularizadas para él mismo, pero símiles a las de sus pares usuarios. La no-identidad es un núcleo de pertenencia de 
COMPRAMORFOSIS. LOS ESPACIOS DE CONSMO

ENTENDIDOS COMO NO-LUGARES

carácter distintivo, ilusorio y consumista que sólo funciona para los no-lugares y que conforma la identidad del individuo (núcleos de pertenencia) junto con los demás elementos de la vida social y particular. Gilberto Giménez (2009) nos explica cómo se conceptualizan la identidad y los núcleos de pertenencia:

Si aceptamos que la identidad de un sujeto se caracteriza ante todo por la voluntad de distinción, demarcación y autonomía con respecto a otros sujetos, se plantea naturalmente la cuestión de cuáles son los atributos diacríticos a los que dicho sujeto apela para fundamentar esa voluntad. Diremos que se trata de una doble serie de atributos distintivos, todos ellos de naturaleza cultural:

1. Atributos de pertenencia social que implican la identificación del individuo con diferentes categorías, grupos y colectivos sociales;

2. Atributos particularizantes que determinan la unicidad idiosincrásica del sujeto en cuestión.

Por lo tanto, la identidad de una persona contiene elementos de lo "socialmente compartido", resultante de la pertenencia a grupos y otros colectivos, y de lo "individualmente único". Los elementos colectivos destacan las semejanzas, mientras que los individuales enfatizan las diferencias, pero ambos se conjuntan para constituir la identidad única, aunque multidimensional, del sujeto individual (Giménez, 2009, 10).

Reforzando esta idea, la identidad, como lo menciona Edward Acton, (2005) "implica una relación fija entre, por una parte la comprensión de uno mismo compartida por el grupo, y por otra, la alianza y el sentido de pertenencia a ese grupo -cuando esa relación es manifiesta y rotundamente variada-" (184). Es así que entendemos la "no-identidad", no como una negación, sino como un complemento de la identidad, como una mixtura de los "(...) sentidos de la palabra rígidos/esencialistas y blandos/constructivistas: los primeros denotan algo 'profundo, básico, permanente, o fundacional' para el 'uno mismo'; en los segundo se hacen concesiones 
con 'la inestable, múltiple, fluctuante y fragmentada' naturaleza del yo contemporáneo (184). La "no-identidad" es parte del individuo y, a pesar de que lo testifica como anónimo, sólo en el no-lugar, desencadena relaciones (contractuales, imaginarias y virtuales) al azar, producto de los particularismos simbólicos que instrumenta el espacio; así "(...) por 'no lugar' designamos dos realidades complementarias pero distintas: los espacios constituidos con relación a ciertos fines (transporte, comercio, ocio) y la relación que los individuos mantienen con esos espacios" (Augé, 2008, 98).

Estas "relaciones" son peculiares, ya que "el espacio del no lugar no crea identidad singular ni relación, sino soledad y similitud" (107). El individuo, a través de su soledad, es productor de un espectáculo para sí mismo y lo único que le permite tener una "relación" es la semejanza del espectáculo que otros individuos producen para sí mismos a la vez, "como si la posición de espectador constituyese lo esencial del espectáculo, como si, en definitiva, el espectador en posición de espectador fuese para sí mismo su propio espectáculo" (91). Este espectáculo no se centra en los individuos, ni en el propio espacio, sino en lo simbólico contractual que procura la utilización del mismo.

El espacio del no-lugar es móvil, es decir, según el momento o el tipo de usuario puede ser un "no-lugar" o un "lugar" como lo hemos analizado anteriormente; por ejemplo, para el viajero el aeropuerto es un "no-lugar", ya que sólo se establece ahí por un corto tiempo, pero para los trabajadores del aeropuerto es un "lugar", ya que ahí han creado identidad, relaciones e historia. Partiendo de este punto podemos determinar que la entrada al espectáculo de los no-lugares se da sólo por lo simbólico contractual que los delimita, sólo para los que tienen el boleto, los que consumen o los que circulan, se vislumbrará el no-lugar y lo podrán habitar.

Finalmente, está claro que es lo simbólico contractual, la esencia del no-lugar, parte de los fines para lo que se crea, como la circulación, el consumo y la comunicación. En la contemporaneidad podemos observar una mutación de lugares tradicionales a no-lugares, "la sobremodernidad (que procede simultáneamente de las tres figuras del exceso que son la superabundancia de acontecimientos, la superabundancia espacial y la individualización de las referencias) encuentra naturalmente su expresión completa en los no lugares" (Augé, 2008, 112). 
Los espacios de consumo están sufriendo procesos de resignificación en función de su estructura simbólica y social. Pero para entender mejor dicho fenómeno y determinar estos procesos es importante, primero analizar el paso del consumo al hiperconsumo, así como su relación con la hiperrealidad ${ }^{10}$ y sus implicaciones sociales.

Hiperconsumo e hiperrealidad: el mercado de ilusiones "La ciudad no se visita, se compra." Walter Benjamin

El consumo en la actualidad ha tomado características de la hipermodernidad, el consumidor común ha adoptado una condición "turbo"11; multiplica sus gustos, adquiere bienes imprevisiblemente y busca en ellos una evolución y confort personal; el valor de uso de los bienes se reemplaza por un valor simbólico, particularizado y virtualizado. Esta nueva etapa del capitalismo simula la realidad del consumo, la hace "hiper", dado que "en el mundo posmoderno no hay realidad, no hay historia, sino un simulacro de la realidad y la negación de la historia" (Arboleda, Masache \& Velasco, 2008, párr. 1). La deslocalización, desterritorialización y virtualización de los hechos nos hacen pensar en una ilusión del espacio o en una realidad alterna.

\section{La simulación imposible}

Hablar de la realidad nos conduce a un camino difícil de abordar. Se puede pensar que todo lo que percibimos con nuestros sentidos es lo que constituye la realidad, pero al compararlo con las subjetividades vecinas aparece una discordancia en la construcción de la misma. ¿Qué es lo verdaderamente real? Esto no es un problema de la individualidad, sino de la colectividad: la sociedad ha creado, de manera consensuada, una realidad legitimada por un constructo simbólico derivado de los procesos de comunicación. La realidad es concebida,

\footnotetext{
10 La hiperrealidad es una condición de la posmodernidad, surge por un desencanto generalizado de lo "real", desencadenado lo ilusorio "virtual", en palabras de Jean Baudrillard (2001), "a la catástrofe de lo real preferimos el exilio de lo virtual, cuyo espejo universal es la televisión". (16). Más adelante se abordará este concepto.

11 Las condiciones contemporáneas han hecho que la vida acelere al punto de desvincular la realidad con los hechos; el individuo se desenvuelve en la sociedad a una velocidad impresionante, en una velocidad "turbo" que lo hace vivir una ilusión de lo que vive y no una realidad.
} 
COMPRAMORFOSIS. LOS ESPACIOS DE CONSMO

ENTENDIDOS COMO NO-LUGARES

según Jean Baudrillard (1978), como una ilusión primaria que es el inicio del mundo, una ilusión radical; esto lo explica mediante una alegoría de la simulación en una fábula de Borges, que versa así:

\section{(...) Los cartógrafos del imperio trazan un mapa tan detallado que llega a recubrir con toda exactitud el territorio (aunque el ocaso del imperio contempla el paulatino desgarro de este mapa que acaba convertido en una ruina despedazada cuyos jirones se esparcen por los desiertos — belleza metafísica la de esta abstracción arruinada, donde fe del orgullo característico del imperio y a la vez pudriéndose como una carroña, regresando al polvo de la tierra, pues no es raro que las imitaciones lleguen con el tiempo a confundirse con el original) (sic) pero ésta es una fábula caduca para nosotros y no guarda más que el encanto discreto de los simulacros de segundo orden (5).}

Baudrillard habla de esta fábula como un simulacro de segundo orden porque en la actualidad tenemos que lidiar con algo más ambiguo: la abstracción simbólica que construimos a partir de la "realidad" no tiene sustancia real, "(...) sino que es la generación por los modelos de algo real sin origen ni realidad: lo hiperreal" (Baudrillard, 1978, 5). El territorio ya no es copiado en el mapa, es el mapa ahora el que delimita al territorio.

Lo real se encuentra supeditado a lo hiperreal porque los procesos de comunicación ya no se dan en un sentido corporalizado, la imagen massmediatizada ${ }^{12}$ nos abre el camino a lo virtual. Somos testigos de guerras, epidemias, manifestaciones, acontecimientos, etcétera, dentro de los cuales "ya no estamos en una lógica de pasar de lo virtual a lo actual, sino en una lógica hiperrealista de disuasión de lo real mediante lo virtual" (15).

Esta virtualidad nos absorbe "(...) mediante toda la estrategia mental de disuasión que se

\footnotetext{
12 Los massmedia son dispositivos que utilizan un modelo de comunicación colectiva basado en "...la unidireccionalidad de la comunicación, la asunción altamente pasiva, sobre todo desde el punto de vista publicitario, de la recepción del mensaje y la ausencia de feedback por parte de las audiencias" (Del Fresno, 2012 , 103). La imagen massmediatizada es la que proporcionan los medios de comunicación masiva (la televisión, la prensa, la radio), es una imagen ilusoria, manipuladora y de sincronicidad virtual, es una imagen que produce y nos muestra lo hiperreal.
} 
ejerce en los hechos y en las imágenes, en la anticipación de lo virtual sobre lo real, en la del tiempo virtual sobre el acontecimiento, y en la confusión inoperable de ambos" (74). Esta confusión y la aceleración de la vida nos somete a la ilusión como algo real porque "lo que necesitamos es el sabor afrodisíaco de la multiplicación, de las falsificaciones, de la alucinación (...)" (86). Debido a lo cruda que puede llegar a ser la realidad, preferimos la desilusión de lo virtual.

La ilusión es nuestra realidad y no otra cosa, el simulacro basado en la nada es nuestra verdad, no existe ni la ilusión ni lo real. Los conceptos de la posmodernidad se desarrollan en lo ilusorio imposible ${ }^{13}$, esto nos impide concebir al hiperconsumo como una ilusión, ahora lo adoptamos como parte de nuestra realidad social y nuestra verdad.

\section{El mercado de ilusiones}

En la actualidad el desarrollo de la globalización y de la sociedad de mercado ha producido grandes cambios en las estructuras sociales, el capitalismo de consumo se ha apoderado de la esfera económica de producción, originando nuevos comportamientos y sistemas de relación entre el individuo y el consumo.

Gilles Lipovetsky (2007) describe la evolución histórica del consumo donde distingue tres etapas principales. La primera se contempla desde 1880 y hasta la Segunda Guerra Mundial, es la aparición del consumo de masas, la producción se intensifica, se crean las marcas, la publicidad del producto y la distribución llega a los rincones menos esperados; podríamos decir que en esta etapa el consumo se democratiza, todos tienen al alcance los productos para poder comprarlos.

13 De acuerdo con la teoría de Jean Baudrillard la ilusión de segundo orden es una ilusión tan parecida a la realidad que la asemeja; pero en la contemporaneidad las ilusiones no contienen naturaleza real, son ilusiones de algo ilusorio, son imposibles e inconcebibles. 
En este proceso "nace una nueva sociedad en la que el crecimiento, la mejora de condiciones de vida, balizas del consumo, se convierten en criterios fundamentales del progreso" (Lipovetsky, 2007, 30); el consumo se frivoliza, la posesión cuantitativa es más importante que la cualitativa, se renuevan los productos y la moda, se otorgan créditos, la publicidad se vuelve simbólica y seductora.

En la segunda etapa el consumidor busca competir simbólicamente a través de los productos que posee, el estatus social se visualiza y espectaculariza a través de lo que compra. Así pues, los individuos se identifican en sus grupos sociales a través de sus pertenencias o el lugar donde las compran, consumir es ser parte de una colectividad específica, el consumo alimenta lo identitario y se logra un standing simbólico del individuo. Esta etapa duró hasta finales de los años 70.

Acompañando "(...) la diversificación extrema de la oferta, la democratización del confort y las diversiones, el acceso a las novedades comerciales se vulgarizó, las regulaciones de clase se disolvieron y aparecieron nuevas aspiraciones y nuevos comportamientos" (Lipovetsky, 2007, 36). La tercera etapa tres se denomina la etapa del hiperconsumo, la particularización del consumo es la principal característica, el consumo emocional (véase Lipovetsky, 2007) e individualizado desplaza al consumo por estatus:

\section{(...) a diferencia del consumo a la antigua, que hacía visible la identidad económica} y social de las personas, los actos de compra de nuestras sociedades expresan ante todo las diferencias de edad, los gustos particulares, la identidad cultural y personal de los agentes, incluso a través de los productos más triviales (...) (Lipovetsky, 2007, 39).

El hiperconsumidor, cuando compra, no busca sólo el bienestar, busca una satisfacción personal, una plenitud psíquica y una conformidad consigo mismo. En la sociedad hiperconsumista ya no se refuerzan los valores identitarios, el consumo consolida la no-identidad de las personas, de modo que los simbolismos individualizados las reafirman como seres únicos y seguros de su esencia. 
Las realidades se multiplican ya que se particularizan, los bienes ya no interesan por su producción ni por su significación en el ámbito social, sino por su participación teatral junto con el individuo en la creación de una realidad única, efímera y dotada de belleza.

El mercado actúa como un bastión de virtualidades, de hiperrealidades potencializadas y satisfactorias, creador de ilusiones que producen "(...) una nueva realidad como máxima entrega. Es decir, una segunda realidad o realidad de ficción con la apariencia de una auténtica naturaleza mejorada, purificada, puerilizada" (Verdú, 2007, 11). El mercado de ilusiones alimenta la desesperanza del mundo — la soledad del individuo - en una ilusión que sólo se vislumbra y es real para él mismo. Se convierte en un simbolismo contractual que muta el entramado social de sus espacios, crea procesos de resignificación en su estructura simbólica y procura nuevos matices en las relaciones de los individuos. Los espacios de consumo tradicionales han cambiado, se han "sobre-significado".

\section{La sobresignificación del espacio de consumo}

"Los espacios de consumo desencadenan un proceso de "democratización del deseo". Al transformar los lugares de venta en palacios de ensueño(...)" Gilles Lipovetsky.

El hiperconsumo ha conseguido infiltrarse en las relaciones personales, en la religión, la cultura, etcétera; en palabras de Lipovetsky (2007), en la contraportada de su obra La felicidad paradójica, "(...) es como si desde este momento, el consumo funcionara como un imperio sin tiempos muertos y de contornos infinitos". Parece que todo se vende y todo se compra, los espacios comerciales nos venden conceptos ilusorios, como el placer, la satisfacción, el deseo y la felicidad.

Estos conceptos acompañan a los bienes que tradicionalmente se ofertaban e incluso parecen dejarlos en un segundo plano, haciendo de la compra una experiencia placentera e individual, una experiencia que testifica la individualidad, mutando el valor de uso de los bienes por un valor simbólico. 
Como ejemplo de esto, cuando vamos a una librería no sólo buscamos un libro, caminamos por todos los pasillos, nos maravillamos con los colores y texturas de las publicaciones, podemos descansar y tomar un buen café, entablar una charla con el vecino de mesa, entretener a los niños en un lugar especial para ellos, participar en conferencias y conciertos programados.

El espacio se ha instrumentado de una multiplicidad de exotismos que crean empatía con el individuo y hacen de su compra una experiencia espectacular que lo absorbe en una realidad ilusoria que lo complace.
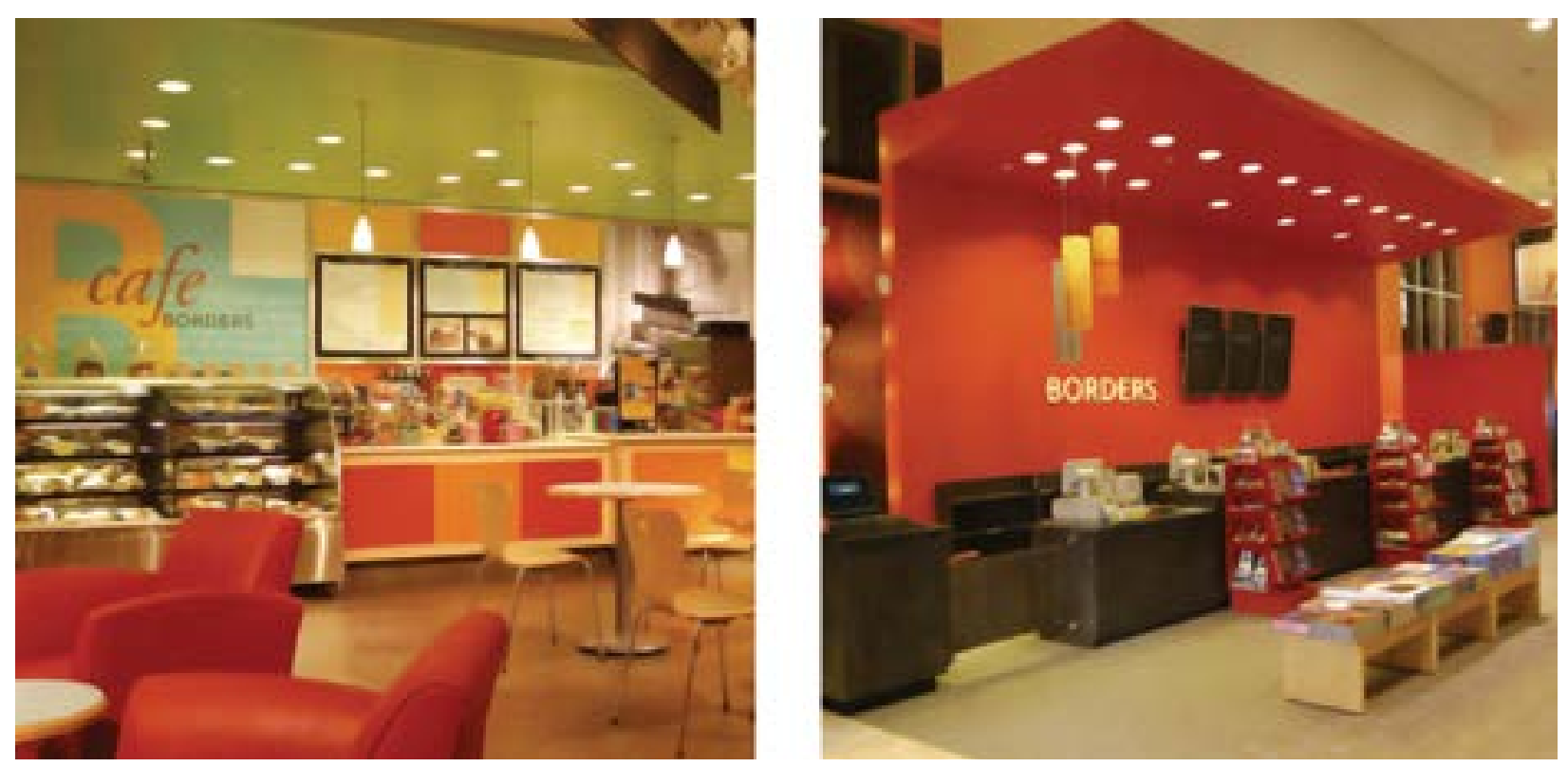

Imagen 1 Fuente: Borders. Louisville, Ky. The Institute of Store Planners (TISP), 2006, 72, 75.

Los grandes espacios de consumo venden más que los bienes materiales adquiridos, venden un estilo de vida y un estilo de mundo "... mediante estrategias de seducción que prefiguran las técnicas modernas de marketing. Impresionar la imaginación, excitar el deseo, presentar la compra como un placer (...)" (Lipovetsky, 2007, 27) se han convertido en la gran promesa del consumo como simbolismo contractual que prefigura las relaciones humanas contemporáneas. 
A diferencia de los espacios de consumo del pasado que sólo buscaban la forma de exhibir de manera adecuada, ordenada y sistemática los productos para su venta, los espacios de consumo en la contemporaneidad funcionan de diferente manera y buscan otro tipo de relación con el usuario. Ahora son espacios donde la experiencia del individuo lo hace sentirse cómodo, donde el standing de consumo sea una forma de pasar el tiempo y de liberarse del peso identitario.

De esta forma el espacio de consumo en la contemporaneidad ha adoptado condiciones de la sobremodernidad, dicha mutación nos permite hablar de que este espacio ha sufrido una sobresignificación ${ }^{14}$.

Cuando hablamos de la sobresignificación del espacio de consumo consideramos diferentes aspectos conceptuales de la sobremodernidad, los cuales se modifican o re-conceptualizan en los espacios de consumo contemporáneos. A continuación analizaremos esta re-significación basados en tres diferentes distinciones, de modo que podamos identificar al espacio de consumo como espacio propio de la sobremodernidad.

\section{Multiplicidad y particularización}

Uno de los conceptos más relevantes de la sobremodernidad es la paradoja multiplicidad-particularización. Vivimos en tiempos de hipermercados, de los grandes almacenes y de los gigantescos malls comerciales, estos espacios se han multiplicado y en ellos podemos encontrar comercios de prácticamente cualquier tipo; la asequibilidad del consumo nos permite tener "a la mano" la oferta de un sinfín de productos, nos encontramos con espacios comerciales dentro de otros espacios comerciales.

Sin embargo, estos espacios multiplicados parecen encontrar su propia estructuración y limitante en la exigencia de que, el espacio de consumo se convierta en un ducto de

14 Es decir, existe una condición de re-significación en la sobremodernidad. 
comunicación y empatía con el comprador. A pesar de contar con diversos espacios comerciales cada uno habla su propio lenguaje, se codifica, simboliza y se hace visible para su perfil de usuario en particular; estos espacios se instrumentan simbólicamente apelando a la idea del "símbolo individualizado": no se crea identidad, historia ni relaciones corporalizadas, más bien instauran la particularización del espacio para lograr empatía, confort y un standing placentero de los usuarios al realizar una compra.

Un muy buen ejemplo de la particularización de los espacios comerciales son los destinados a los niños. En las primeras fases del consumo eran espacios como todos, donde sólo se exhibían los productos para poder adquirirlos, incluso era molesto y aburrido para los chicos acompañar a mamá a comprar, sin embargo, la "sobre-significación" del espacio ha hecho de estos comercios espacios de diversión para los niños, es como un juego y se disfruta totalmente ir de compras; estos espacios han sido instrumentados simbólicamente para que los chicos identifiquen el lugar como un espacio de juegos, de ilusiones y diversión.
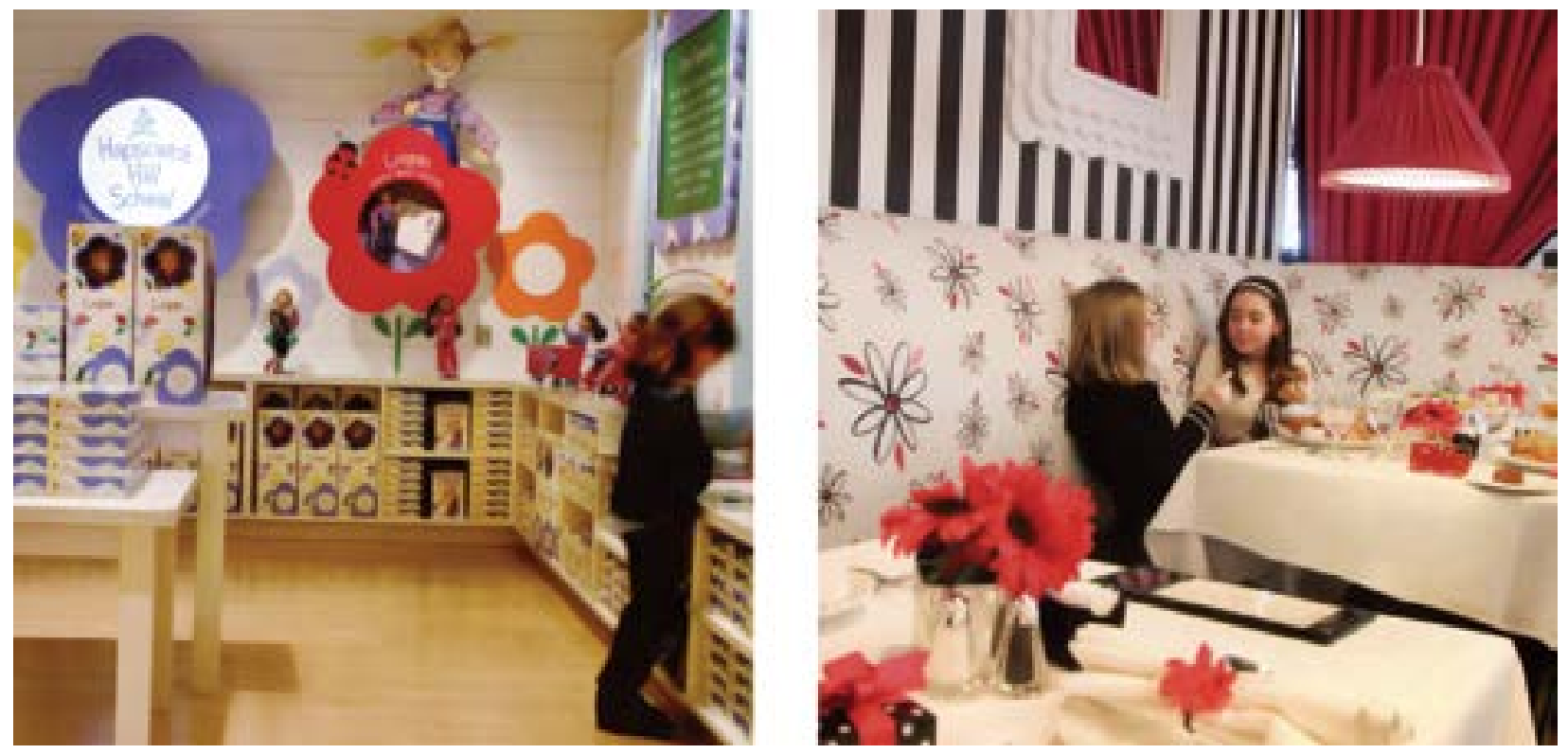

Imagen 2 Fuente: American Girl Place. New York. TISP, 2006, 79 
Los particularismos simbólicos que llenan el lugar hacen que sólo el individuo lo asimile como único, se vislumbra ante él como un espacio comercial y desaparece para el resto de la realidad, actúa en lo individualizado, no en lo colectivo. La no-identidad del individuo se hace visible en estos espacios.

\section{El consumo emocional}

Otro aspecto conceptual de la sobresignificación en los espacios de consumo es el consumo emocional. Al particularizar simbólicamente el espacio comercial el consumo deja de ser una actividad de entrada por salida, ya no es una actividad obligatoria y desgastante, ahora se ha convertido en un pasatiempo, incluso en una actividad para distraerse de lo cotidiano: "(...) los centros comerciales y las tiendas de última tendencia aspiran a reencarnar las actitudes y lugares de venta a transformar las zonas de tiempo obligatorio en zonas de tiempo de placer" (Lipovetsky, 2007, 61).

Visitar un centro comercial o un hipermercado en la contemporaneidad es una experiencia sensorial. Se disfrutan los colores, los olores, los sonidos, las relaciones efímeras que se dan lugar ahí; el tiempo que se pasa comprando no es tiempo perdido o aburrido, es tiempo de distracción y de placer, el hedonismo consumista se maximiza.

Los espacios de consumo se han adecuado para cubrir las necesidades del usuario y agregar confort y una experiencia placentera, "en sintonía con el hiperconsumidor emocional están los comercios de nuevo cuño que se dedican a intensificar el componente placentero del acto de compra, para que los consumidores vivan experiencias afectivas y sensoriales" (77).

El consumo ha dejado de ser un acto totalmente funcional y ha mutado a uno emocional, las lovemarks ${ }^{15}$ son la mayor prueba de ello, la idea del consumo emocional "(...) navega viento en popa en las aguas de los teóricos y agentes de la mercadotecnia, que exageran

15 El término, que refleja lo mismo que I love brand, se refiere no solamente a un artículo de buena calidad, sino a una atmósfera en la que el individuo se ve inmerso al hacer uso de él, despertando el sentido emocional y afectivo. 
los méritos de las gestiones que permiten que los consumidores vivan experiencias afectivas, imaginarias y sensoriales" (40).
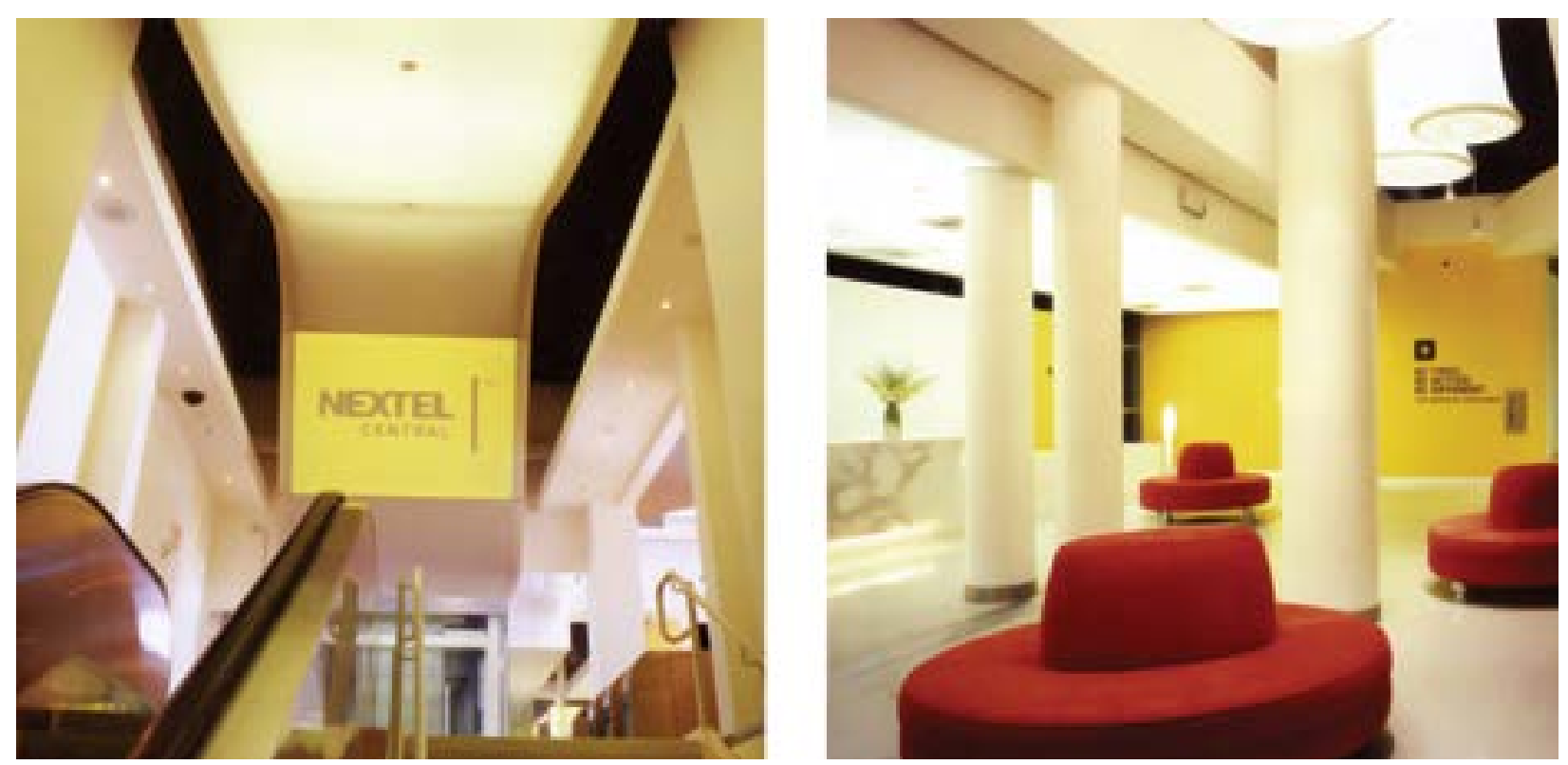

Imagen 3 Fuente: Nextel Central. Las Vegas. TISP, 2006, 132-133.

Una realidad alterna e ilusoria invade al espacio, la compra por la simple compra ya no tiene cabida, ahora la experiencia y los valores simbólicos que lo llenan es lo que el individuo valora y con los cuales siente empatía. La imagen 3 ilustra cómo un simple espacio de atención a clientes y ventas, comunica simbólicamente el valor principal de Nextel, la "exclusividad", ésta se espectaculariza a través del loft, las terrazas, el mobiliario y el personal. Todo en él se conjunta e instrumenta para hacer de la visita del cliente una experiencia única y emocional.

\section{El concepto abierto-cerrado}

Hemos establecido una delimitación conceptual que nos permite un mejor análisis de los espacios de consumo en función de las distinciones de multiplicidad-particularización y consumo emocional que ya hemos revisado. En este mismo sentido se propone una división 
tipológica del espacio comercial, de acuerdo a las características de la sobremodernidad, en espacios de consumo cerrados y espacios de consumo abiertos.

El espacio de consumo cerrado es aquél que se encuentra estructurado dentro de un centro comercial, su conceptualización formal es la del consumo; en este tipo de espacios el individuo acude en busca de adquirir un producto o servicio. De acuerdo con Marc Augé estos espacios son por antonomasia los súper e hipermercados y las cadenas hoteleras. En la imagen 4 se nos muestra un espacio de consumo cerrado, cuyas características de standing refuerzan los conceptos de particularización y consumo emocional antes mencionados. Este espacio está instrumentado simbólicamente ex profeso para los fines de seducción y consumo que hemos analizado anteriormente.
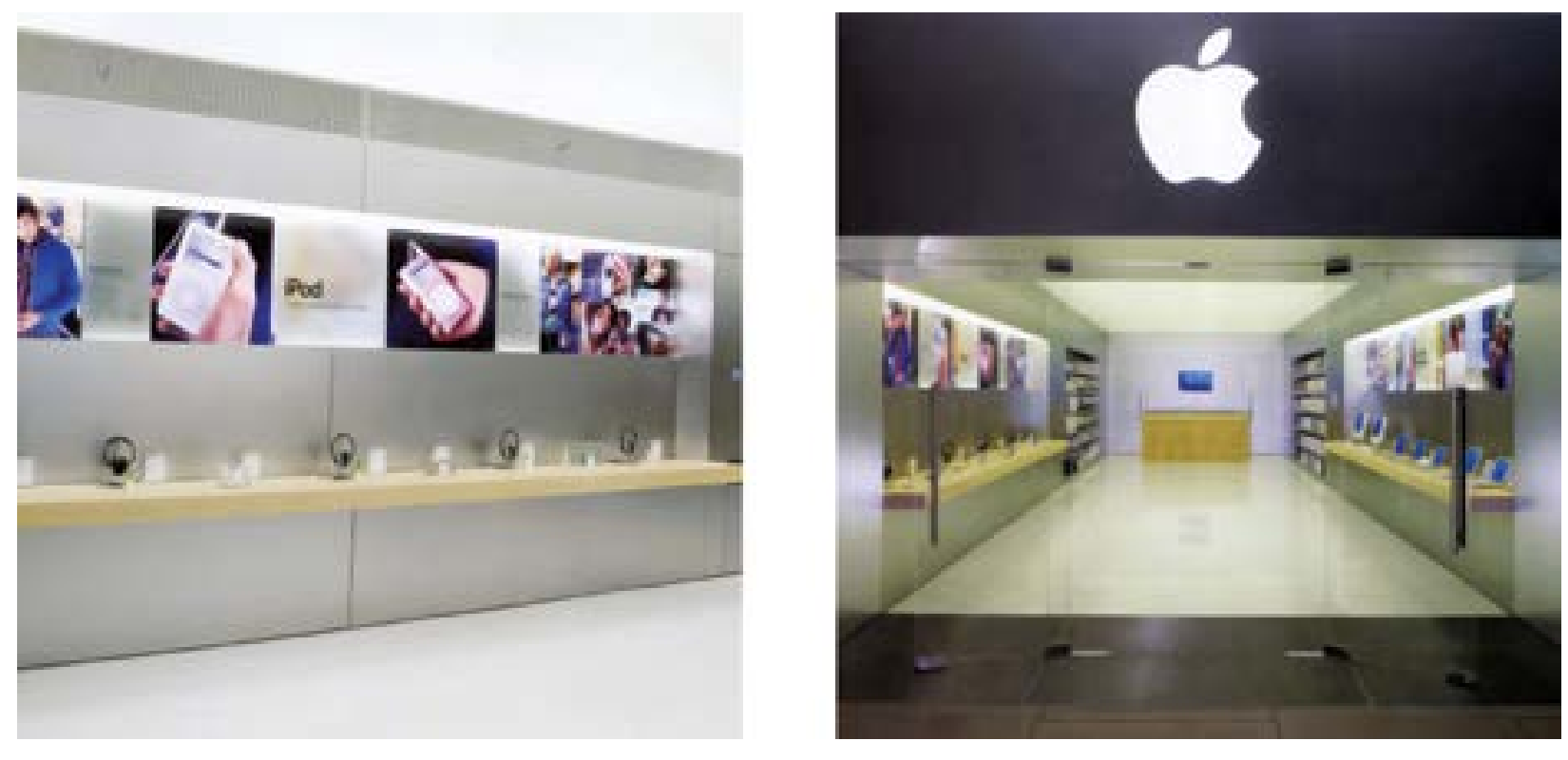

Imagen 4 Fuente: Apple Mini Store, Palo Alto California. TISP, 2006, 164-165.

Por otro lado, los espacios de consumo abiertos, son aquellos situados casualmente en nuestros espacios de circulación o comunicación, podemos encontrarlos en nuestra estadía en lugares como autopistas, aeropuertos o áreas de servicio de las gasolineras, o podemos llegar a ellos a través de lo inmaterial, a través de la pantalla de nuestro celular o a través 
COMPRAMORFOSIS. LOS ESPACIOS DE CONSMO

de la propia computadora. La imagen 5 nos ejemplifica un espacio de consumo abierto, en este caso, dentro de un aeropuerto este espacio sólo se "abre" a través del simbolismo contractual del boleto de viajero, sólo por una horas el individuo lo habita creando relaciones efímeras a partir de su particularidad.

La aproximación tipológica "abierto-cerrado" nos permite establecer una sobresignificación de los espacios de consumo entendiéndolos como no-lugares, ya que su existencia empírica y efímera ejemplifica las condiciones que hemos establecido previamente para ser considerados verdaderos espacios de la sobremodernidad.
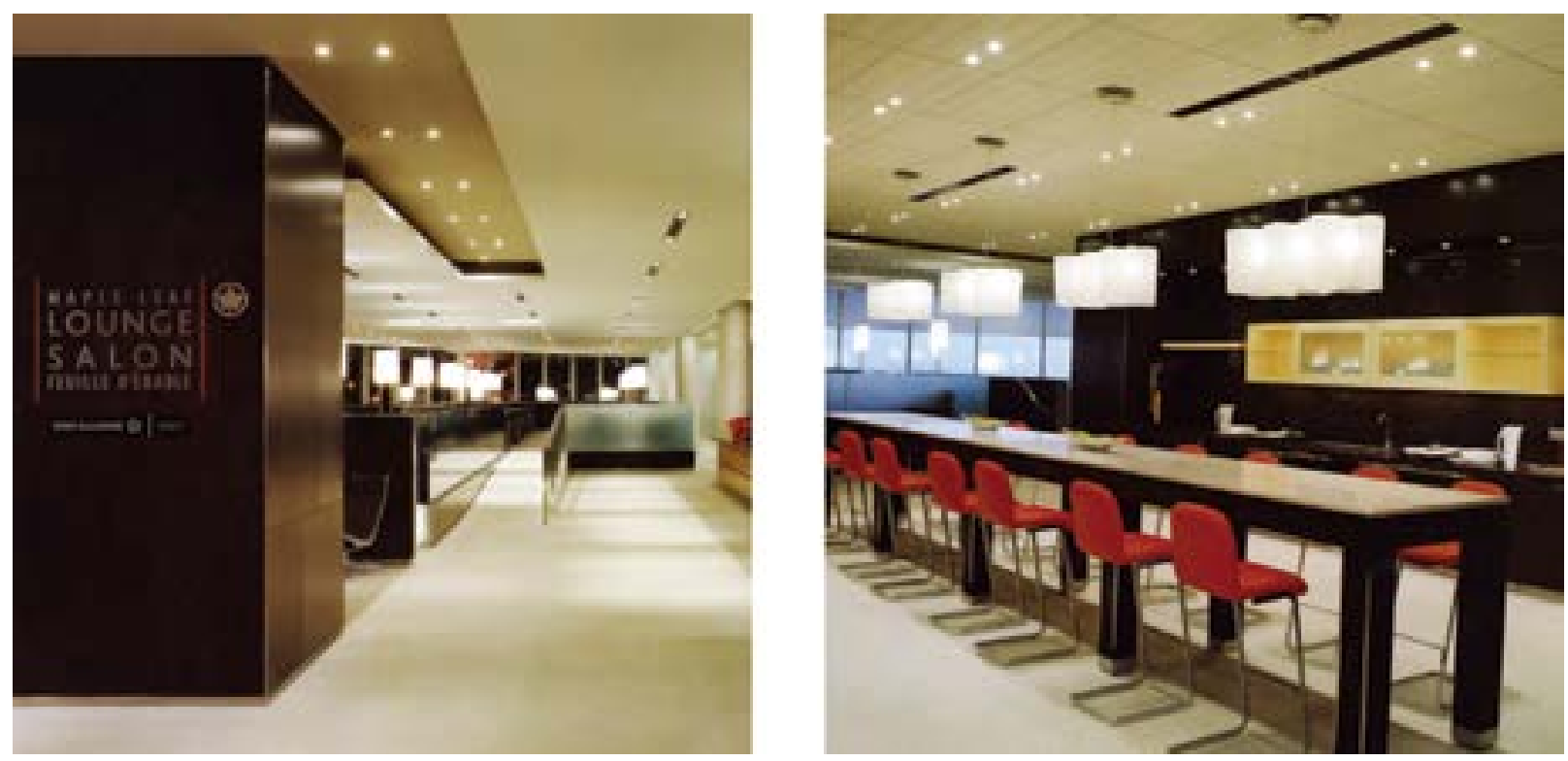

Imagen 5 Fuente: Air Canada Maple Leaf Longe, Pearson International Airport, Toronto.TISP, 2006, 124-125. 


\section{Conclusiones}

Como hemos visto, uno de los aspectos más relevantes de la cultura contemporánea es la aparición de diversos y nuevos espacios donde el hombre aprehende y se hace partícipe activo de la realidad social; espacios efímeros donde se desarrolla el entramado social que presupone las relaciones humanas. Un ejemplo de estos espacios propios de la sobremodernidad son los no-lugares; espacios de anonimato donde el individuo se instala en un momento de espera y crea relaciones efímeras y fugaces con demás individuos en condiciones similares; relaciones furtivas de personas que nunca más se encontrarán.

En este sentido, los no-lugares subrogan lo identitario y lo histórico, al descorporalizar y deslocalizar el acto comunicativo se convierten en un acto de simulación de la realidad; la comunicación se virtualiza a través de imágenes y símbolos, actúa en lo que llamamos la hiperrealidad, lo valores de uso o identitarios no actúan más, lo simbólico individualizado ha establecido sus condiciones en la sociedad contemporánea. El imperio hiperconsumista ha propiciado la aparición y desarrollo de los no-lugares, ya que se busca un mejor standing - hedonista y emocional - de los usuarios en el espacio de consumo; se crean condiciones de comodidad, de libertad y de empatía, lo cual procura relaciones efímeras entre los usuarios; todas estas característica propias del no-lugar.

Según lo expresa Marc Augé (2008) en la contraportada de su obra Los no lugares, el usuario de éstos "... mantiene una relación contractual establecida por el billete de tren o de avión y no tiene en ellos más personalidad que la documentada en su tarjeta de identidad". Esto nos permite identificar al hiperconsumo como un mecanismo simbólico-contractual, ya que los individuos que usan los espacios de consumo no adoptan otro núcleo de pertenencia más que su condición de consumidores. Lo que hemos llamado "no-identidad" funciona a la entrada y salida del no-lugar, dentro de él los valores individualizados, las relaciones efímeras y los sistemas simbólicos son los que relacionan al individuo con el espacio.

La actividad de asistir a un centro comercial sólo para comprar ha quedado en el pasado, todas las condiciones conceptuales expuestas en el presente trabajo nos permiten entender el proceso de resignificación o "sobresignificación", como lo hemos llamado, de los 
espacios de consumo en la contemporaneidad. En suma, se describieron las condiciones simbólicas del consumo y sus espacios: ir de compras es más que la propia acción a la que se hace referencia, ir de compras es una experiencia emocional, multiforme e infinita. Es así que, el consumo se ha convertido en el simbolismo contractual que permite la entrada y salida al no-lugar, los espacios de consumo contemporáneos se han convertido en uno de éstos, han adoptado condiciones sobremodernas y se han "sobre-significado".

En este punto es importante señalar la pertinencia de comprender esta "sobre-significación" del espacio de consumo. El analizar cómo el hombre se convierte en un elemento más en los conjuntos de signos al servicio del consumo; nos permite acercarnos a entender cómo la soledad humana deriva en procesos de intercambio comercial, en función de espacios con simbolismos instrumentados por la mercadotecnia, el diseño y la publicidad contemporáneos.

El divulgar el análisis que se ha establecido en el presente escrito, podría dar pie a la búsqueda de nuevas metodologías, proyectos y conceptos que lleven a las diferentes disciplinas que participan de la instrumentación de los espacios, a ser parte de la construcción de nuevos conceptos y nuevas tendencias tanto formales como estéticas, encaminadas a la búsqueda de una conceptualización antropológica de este fenómeno contemporáneo. En medida de que se desarrollen estudios, se creen conceptos y se participe en proyectos de multidisciplina social, se estará más cerca de tener cabida en la historia del mundo actual y no sólo ser un simple espectador del devenir social.

Finalmente, es importante señalar que la transformación significante que sufren, en la sobremodernidad, los espacios de consumo, hace que las relaciones humanas que se desarrollan en su interior muten junto con ellos y acompañado con los anteriores planteamientos, tenemos que preguntarnos ¿cuáles son las nuevas formas de relación humana propias de la contemporaneidad que se desarrollan en sus diferentes espacios? 


\section{Referencias}

Abbate, F. \& Páez, P. (2007). Gilles Deleuze para principiantes. Argentina: Lectorum.

Acton, E. (2005). La biografía y el estudio de la identidad. En J. C. Davis e Isabel Burdiel (Eds.), El Otro, el mismo. Biografía y autobiografía en Europa (siglos XVII-XX) (177-198). España: Universidad de Valencia.

Arboleda, C.; Masache, J. \& Velasco, D. (2008.10.31). Internet, ideología global, [Blog]. Recuperado de http://ideologiainternet.blogspot. mx/2008/11/el-simulacro-no-es-lo-que-oculta-la.html

Augé, M. (2008). Los no lugares. Espacios de anonimato. Una antropología de la sobremodernidad. Barcelona: Gedisa.

(2009). Sobremodernidad. Del mundo de hoy al mundo de mañana. Recuperado de https://asodea.files.wordpress.com/2009/09/auge-marcsobremodernidad.pdf

Baudrillard, Jean (1978). Cultura y Simulacro. Barcelona: Editorial Kairos.

(2001). La Guerra del Golfo no ha tenido lugar. Barcelona: Anagrama.

Bourdieu, P. (2002). Lección sobre la lección. Barcelona: Anagrama.

David, C. \& Virilio, P. (2009). Alles Ferting: se acabó (una conversación). [Entrevista] Recuperado de https://www.uclm.es/profesorado/ juanmancebo/descarga/docencia/movimientos/conversacion.pdf

De Certeau, M. (2007). La invención de lo cotidiano. 1. Artes de hacer. México: Universidad Iberoamericana.

Del Fresno, M. (2012, septiembre-noviembre). Comprendiendo los social media y mass media: un modelo para el estudio de la comunicación interpersonal colectiva en tiempos de Internet. Derecom,(1), Nueva Época, 99-109.

Giménez, G. (2009). La cultura como identidad y la identidad como cultura. Recuperado de http://perio.unlp.edu.ar/teorias2/textos/articulos/ gimenez.pdf

Guerra Manzo, E. (2010, mayo-agosto). Las teorías sociológicas de Pierre Bourdieu y Norbert Elias: los conceptos de campo social y habitus. Estudios Sociológicos, XXVIII, 383-409.

Lacarrieu, M. (2013, enero-junio). Entre el 'lugar antropológico' y el 'lugar disputado': hacia una 'antropología del lugar'. Sociedade e Cultura, 15-26.

Lipovetsky, G. (2007). La felicidad paradójica. Ensayo sobre la sociedad de hiperconsumo. Barcelona: Anagrama.

McLuhan, M. \& Powers, B. R. (1995). La aldea global. Barcelona: Editorial Gedisa.

The Institute of Store Planners (TISP) (2006). Stores and Retail Spaces 7. New York: ST Books.

Vattimo, G. (1990). La sociedad transparente. Barcelona: Paidós/ICE-UAB.

Verdú, V. (2007). El estilo del mundo. La vida en el capitalismo de ficción. Barcelona: Anagrama.

Vidal, M. (2007). La inutilidad de las pasiones. Desidentificación del sujeto (pos)moderno en "Una pasión inútil" de Cristina Peri Ross. Recuperado de http://repositorio.uchile.cl/handle/2250/110464 